\title{
Use of Ultraviolet Blood Irradiation Against Viral Infections
}

\author{
Alberto Boretti ${ }^{1}\left[\right.$. Bimal Banik ${ }^{1} \cdot$ Stefania Castelletto ${ }^{2}$ \\ Accepted: 21 September 2020 / Published online: 7 October 2020 \\ (c) Springer Science+Business Media, LLC, part of Springer Nature 2020
}

\begin{abstract}
Ultraviolet blood irradiation (UBI) was used with success in the 1930s and 1940s for a variety of diseases. Despite the success, the lack of understanding of the detailed mechanisms of actions, and the achievements of antibiotics, phased off the use of UBI from the 1950s. The emergence of novel viral infections, from HIV/AIDS to Ebola, from SARS and MERS, and SARS-CoV-2, bring back the attention to this therapeutical opportunity. UBI has a complex virucidal activity, mostly acting on the immune system response. It has effects on lymphocytes (T-cells and B-cells), macrophages, monocytes, dendritic cells, low-density lipoprotein (LDL), and lipids. The Knott technique was applied for bacterial infections such as tuberculosis to viral infections such as hepatitis or influenza. The more complex extracorporeal photopheresis (ECP) is also being applied to hematological cancers such as T-cell lymphomas. Further studies of UBI may help to create a useful device that may find applications for novel viruses that are resistant to known antivirals or vaccines, or also bacteria that are resistant to known antibiotics.
\end{abstract}

Keywords UV light $\cdot$ UBI $\cdot$ DNA repair $\cdot$ Blood cells $\cdot$ Antigen-presenting cells $\cdot$ Viral infections $\cdot$ Cytokines

\section{Introduction}

The interaction of light with matter such as proteins, molecules, and atoms, as well as biological samples from viruses to bacteria and cells, is at the core of many fundamental sciences and methods currently used in diagnostics and therapeutics. The electromagnetic spectrum incorporates a large range of frequencies, wavelengths, and photon energies. Ultraviolet (UV) light covers a range of emission wavelengths from 10 to $400 \mathrm{~nm}$, thus with energy higher than the visible light but below X-rays energy. Wavelength and frequency (photons energy) are related through the speed of light, $\lambda \cdot \nu=c$, where $c$ $=299,792,458 \mathrm{~m} / \mathrm{s}$ is the speed of light. Table 1 presents the spectral range, frequency, and energy properties of classified UV light.

UV light in the range 240 to $280 \mathrm{~nm}$ wavelength is used for disinfection and decontamination of surfaces and water, and it is applied by germicidal lamps. DNA and

Alberto Boretti

a.a.boretti@gmail.com

1 Prince Mohammad Bin Fahd University, 31952 Al-Khobar, Saudi Arabia

2 RMIT University, VIC 3083 Bundoora, Australia
RNA absorption has a peak at $260 \mathrm{~nm}$, and spectroscopy is commonly used to determine the average concentrations of the nucleic acids DNA or RNA present in a mixture, as well as their purity. The UV germicidal action is a wellknown method for killing or inactivating microorganisms by damaging their nucleic acids and unsetting their DNA. UV light is also used in food preparation.

UV light of 300 to $320 \mathrm{~nm}$ wavelength is used for light therapy in medical applications. Ultraviolet B (UVB) $311 \mathrm{~nm}$ narrowband lamps are used for example in phototherapy to cure psoriasis or T-cell cutaneous lymphoma such as mycosis fungoides.

Here, we specifically examine the possible virucidal activity of UV light for infection such as the SARS-CoV-2 virus, Fig. 1. The SARS-CoV-2 virus is 60 to $100 \mathrm{~nm}$ in diameter. UV has been proposed as (1) a tool to inactivate the airborne viruses, as well as (2) a device to inactivate or prevent replication of the viruses in infected patients acting through the blood.

Regarding (1), it has been envisaged that the development of far-UV lamps could be beneficial in the inactivation of the SARS-CoV-2 virus based on [1-18].

Regarding the other aspect (2) of UV light use, the indirect action on the immune system by ultraviolet blood irradiation (UBI) has been considered in the far past [19-99]. 
Table 1 Properties of UV light

\begin{tabular}{|c|c|c|c|c|c|c|c|c|c|}
\hline \multirow[t]{2}{*}{ Name } & \multirow[t]{2}{*}{ Abbreviation } & \multicolumn{2}{|c|}{ Wavelength } & \multicolumn{2}{|c|}{ Frequency } & \multicolumn{4}{|c|}{ Photon energy } \\
\hline & & $\mathrm{nm}$ & & $\mathrm{THz}$ & & $\mathrm{eV}$ & & $\mathrm{aJ}$ & \\
\hline Ultraviolet A & UVA & 400 & 315 & 749 & 952 & 3.10 & 3.94 & 0.497 & 0.632 \\
\hline Ultraviolet B & UVB & 315 & 280 & 952 & 1071 & 3.94 & 4.43 & 0.632 & 0.710 \\
\hline Ultraviolet C & UVC & 280 & 100 & 1071 & 2998 & 4.43 & 12.40 & 0.710 & 1.988 \\
\hline Near ultraviolet & NUV & 400 & 300 & 749 & 999 & 3.10 & 4.13 & 0.497 & 0.662 \\
\hline Middle ultraviolet & MUV & 300 & 200 & 999 & 1499 & 4.13 & 6.20 & 0.662 & 0.994 \\
\hline Far ultraviolet & FUV & 200 & 122 & 1499 & 2457 & 6.20 & 10.16 & 0.994 & 1.629 \\
\hline Hydrogen Lyman-alpha & H Lyman- $\alpha$ & 122 & 121 & 2457 & 2478 & 10.16 & 10.25 & 1.629 & 1.643 \\
\hline Vacuum ultraviolet & VUV & 200 & 10 & 1499 & 29979 & 6.20 & 12.40 & 0.994 & 1.988 \\
\hline Extreme ultraviolet & EUV & 121 & 10 & 2478 & 29979 & 10.25 & 12.40 & 1.643 & 1.988 \\
\hline
\end{tabular}

While the air disinfection in public buildings via upperroom germicidal far-UV light may reduce the airborne viral transmission of SARS-CoV-2, UBI may be used as a natural antiviral in infected patients. In the case of UBI, the principle of action is different from far-UV, as UV is acting mostly as an enhancer of the immune system rather than a direct killer of the viruses. UBI exposes the blood to UV light to amplify the immune system response and kill the viruses. The ways UBI acts on the immune system are everything but well established, the same as the antiviral effects. The many far past experiences demonstrated the technique was helpful for many pathologies; however, it was administered without a clear detailed understanding of the mechanisms of action.

Viruses absorb much more energy than the red and white blood cells and get more damaged by UV light. The killed viral fragments create a vaccination-like response. This strengthens the immune system response to the specific pathogen. This may explain why treating only a small amount of blood with UBI may induce a significant immune system response. UBI is in principle an immune-modulating therapy, which may help also with viral infections. It has never been tested so far for SARS-CoV-2.

This work aims to review the literature concerning the uses of UV light that could be beneficial for SARS-CoV-2 infection, in air, but especially through the blood via UBI. The more complex extracorporeal photopheresis (ECP), which is under certain aspects an evolution of the Knott UBI being applied to hematological cancers such as T-cell lymphomas, is here only mentioned, but not discussed into details. The mechanism of action of ECP is also not completely understood [100-105]. It is believed that a combination of psoralen and UVA radiation causes apoptosis (programmed cell death) of some of the affected $\mathrm{T}$ cells, which returned to the body, trigger the immune system to recognize antigens on the $\mathrm{T}$ cells and destroy them. The less-damaged monocytes phagocytose apoptotic $\mathrm{T}$ cells. Monocytes exposed to radiation progress into dendritic cells that diminish the immune response.

\section{Direct UV Antiviral Effects in Air}

UV light has significant effects on airborne viruses. Far-UV is capable to deactivate viruses [1]. UV has shown effects on the sterilization of materials. The use of ultraviolet light against airborne disinfection was first demonstrated more than 8 decades ago [2]. Far-UVC may become effective against all types of airborne viruses including new strains. It may also reduce the transmission of influenza and other respiratory viruses. It may work against SARS-CoV-2. Airborne-induced microbial diseases such as tuberculosis may also be targeted. An approach to stop airborne pathogen spread with UVC radiation is being established. The airborne antimicrobial efficacy of UV light has long been recognized through a direct method [3-5]. Germicidal UV light is capable of inactivating both drug-sensitive and multi-drug-resistant bacteria [6] and different strains of viruses [7]. Despite the importance, the use of germicidal ultraviolet light among the public remains limited because of the phototoxicity of the conventional UVC light which is carcinogenic and cataractogenic [8, 9]. In contrast, low-power far-UVC light with a wavelength from 207 to $222 \mathrm{~nm}$ efficiently deactivates viruses and bacteria without damaging the skin or the eyes [10-12]. Due to its short wavelength, far-UVC light does not penetrate the nonliving outer layers of the human skin or eyes, while since the sizes of the bacteria and the viruses are much smaller (as previously written, the SARS-CoV-2 virus is 60 to $100 \mathrm{~nm}$ in diameter), far-UVC light can penetrate and inactivate such small organism [10-12].

The germicidal efficacy studies of far UVC light [10-15], were performed by exposing bacteria on a surface or in suspension to the irradiation. A major pathway for the spread of influenza A virus is through aerosol transmission. The same is true for SARS-CoV-2. In [1], far-UVC light of 222-nm wavelength efficacy used to inactivate airborne viruses carried by aerosols was also 
Fig. 1 a Scanning electron microscope image shows SARSCoV-2 (yellow) emerging from the surface of cells (blue/pink) cultured in the lab. Credit: NIAID-RML. b Transmission electron microscope image of SARS-CoV-2 virus particles shown emerging from the surface of cells cultured in the lab. Credit: NIAID-RML
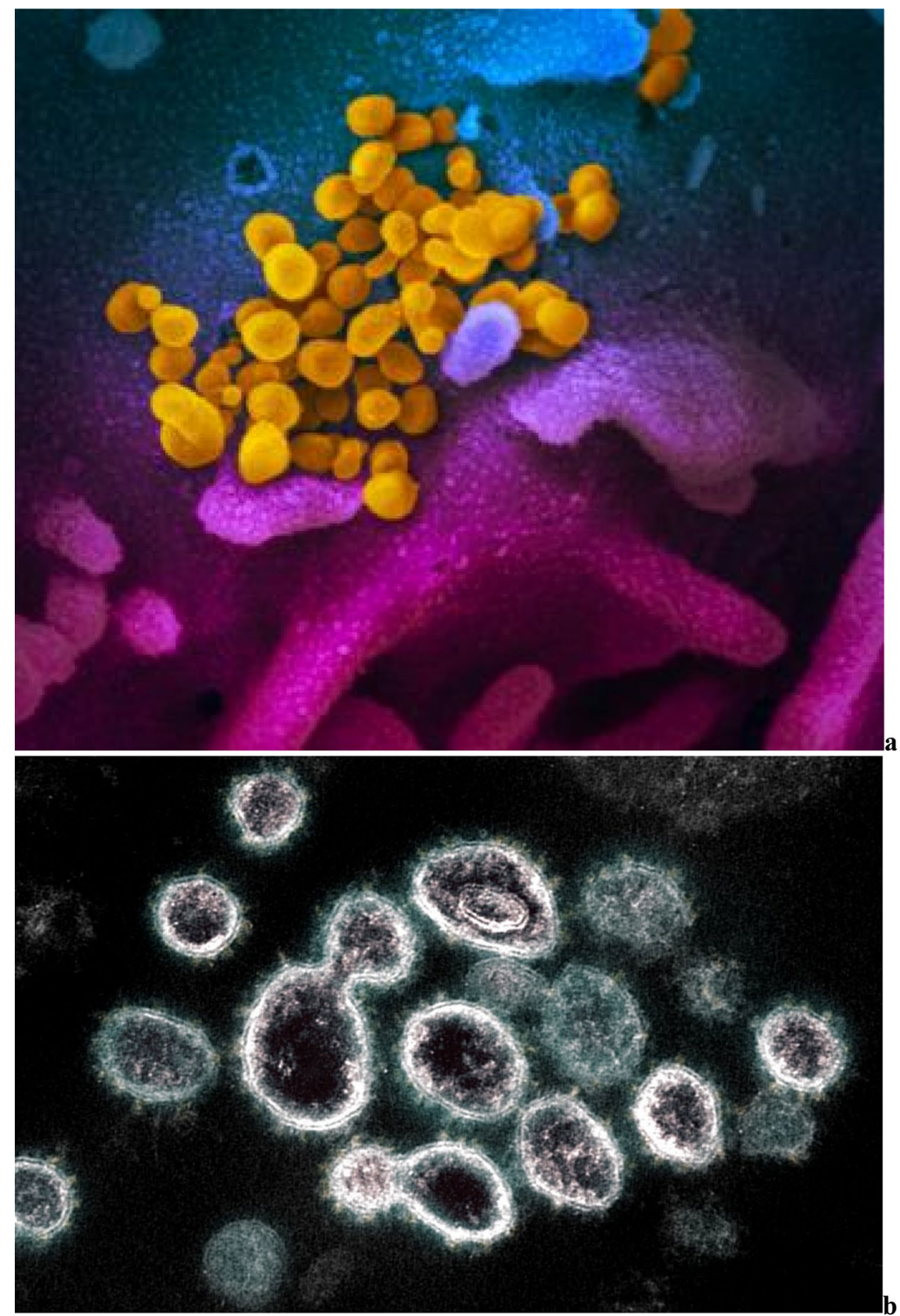

compared to conventional 254-nm germicidal lamps used to inactivate airborne microbes. The 222-nm far-UVC light was used to deactivate the influenza A virus (H1N1) carried by aerosols using a UV irradiation chamber. The chamber generated aerosol droplets like those generated by human coughing and breathing. The aerosolized viruses in the irradiation chamber were exposed to UVC lamps.
Inactivation of $\mathrm{H} 1 \mathrm{~N} 1$ with the 222-nm far-UVC light followed an exponential disinfection model, with an inactivation cross section of $\mathrm{D}_{95}=1.6 \mathrm{~mJ} / \mathrm{cm}^{2}$. For a comparative study, using a similar experimental procedure with a standard $254 \mathrm{~nm}$ germicidal UVC lamp, [16] identified a $D_{95}$ value of $1.1 \mathrm{~mJ} / \mathrm{cm}^{2}$ for the $\mathrm{H} 1 \mathrm{~N} 1$ virus. A $222-\mathrm{nm}$ far-UVC light and 254-nm broad-spectrum germicidal light 
had similar results for aerosolized viral inactivation, with the advantage that far-UV is not harmful to humans. Both regions of the spectrum were found to be effective in the inactivation. The exact cause of inactivation may not be identical $[17,18]$. Opposite to standard germicidal broadspectrum UVC light of 254-nm wavelength, far-UVC light is not cytotoxic to human cells/tissues in vitro or in vivo [10-12]. Thus, spreading the SARS-CoV-2 virus in open spaces such as halls occupied by a large number of peoples could be prevented safely by using this technique.

\section{Direct and Indirect UV Antiviral Effects in Blood}

In addition to the use of the antiviral properties in the air mentioned above, the UV UBI is certainly a fascinating opportunity to work against viral infections in patients [19]. This technique has been popular, but then it has been forgotten in time. UBI was already used 80 years ago on a routine basis to treat numerous diseases. These diseases included asthma, septicemia, tuberculosis, pneumonia, arthritis, and poliomyelitis. The discovery of antibiotics of higher commercial values and the poorly understood mechanisms of action of UBI overlooked the benefits of UBI. The initial studies were performed by numerous physicians in the USA starting from 1928. Then, studies were also conducted by scientists in Russia and East European countries when the technique was dismissed in the West during the 1950s. The use of UBI remains mostly controversial. Due to the development and usefulness of antibiotics, the application of UBI declined rapidly. Although very crucial, it has now been almost completely forgotten. However, UBI is an attractive approach to treat infections. This is used as a therapy for immune-modulation and as a parameter for normalizing the blood parameters. The resistance of microorganisms in the blood to UV irradiation is not fully understood. A low and mild dose of $\mathrm{UV}$ is effective in killing microorganisms by inhibiting their DNA synthesis. The important observation is that any type of DNA damage in the host cells is repaired by the DNA repair enzymes. But, it is understood that the action of UBI to manage septicemia is not due to UV-induced killing of bacteria in the blood only. An approximately 5-7\% of blood is necessary for the treatment with UV to have the optimum benefit. UBI enhances the phagocytic ability of numerous neutrophils and dendritic cells, inhibits lymphocytes, and oxidizes the blood lipids [19]. Thus, the oxidative power of UBI has mechanisms in common with other therapies such as ozone therapy or oxygen therapy. Similarities between ECP with psoralens and UBI also exist [19]. But, significant differences between UBI and ECP are found in their mode of action. For example, UBI stimulates the immune system, while the ECP process is immunosuppressive. The UBI method should be investigated in detail as a separate method to treat infections and immunity-related medical disorders [19].

The first human treatment using UBI was performed in 1928. Due to this process, the case of hemolytic streptococcus septicemia was successfully treated [20]. A similar success was observed in a patient who had advanced hemolytic streptococcal septicemia [21]. UBI was then investigated for pneumonia patients. It was crucial to see that all the 75 patients of the trial responded well to UBI. The time of hospital stay was decreased, and the acceleration of convalescence was observed [22].

It is important to state the specific UBI technique developed by Knott. This process involved removing approximately $3.5 \mathrm{~mL} / \mathrm{kg}$ of venous blood, citrating it as an anticoagulant, and then passing it through a radiation chamber. The exposure time per unit of blood was selected at $10 \mathrm{~s}$. The wavelength of light was set at $253.7 \mathrm{~nm}$. The UVC was obtained by a quartz burner of mercury. The blood was re-perfused as quickly as possible [20]. This method was applied to many diseases including thrombophlebitis, staphylococcal septicemia, peritonitis, botulism, poliomyelitis, non-healing wounds, and asthma as shown in [21-35]. Twenty-nine other different medical disorders were also treated successfully, including infectious arthritis, septic abortion, osteoarthritis, tuberculosis glands, chronic blepharitis, mastoiditis, uveitis, furunculosis, chronic paranasal sinusitis, acne vulgaris, and secondary anemia [36, 37]. UB was also applied to Escherichia coli septicemia, post-abortion sepsis, puerperal sepsis, peritonitis, and typhoid fever [38-42]. Efficacy for biliary disease, pelvic cellulitis, and viral hepatitis was also demonstrated [43-45].

The mechanisms of how UBI works against infections and modulates the immune system are discussed in [19]. Although known for the past 90 years, the detailed description of the mechanisms of action UBI is not available yet. Therefore, there has been always confusion in the use of this radiation for medical purposes. As stated before, UV demonstrated effects in the sterilization of water and surgical instruments. On this basis, it was believed that the use of UV against infection also depended on the direct destruction of the pathogens. Confusion also exists since UBI was used to treat a wide diversity of diseases.

The UBI is capable of altering many properties of blood as well as leukocytes as demonstrated by in vitro results. For example, the UVI increases the percentage of stimulating cells in leukocytes and controls mitogen-induced media. Importantly, the UVI can reverse the production of cytokine and block its release. It also disturbs cell membrane stabilization. The UBI has numerous effects on red blood cells. Anaerobic situations can inhibit the process because UV light can induce the removal of potassium ion from the 
cells. Kabat et al. [46] had proved that UV radiation can alter the osmotic characteristics of red blood cells, their submicroscopic structures, and the breakdown of specific nucleotides. Different irradiation periods ranging from 1 to $5 \mathrm{~h}$ were chosen to investigate these roles. This study showed that a decreased value of ATP increases the values of other nucleotides. The UV radiation also increased the hypotonic sodium and potassium cation values and the ratio of the red blood cells [46].

Irradiation of Rh-positive blood with UV light increases the immune adsorption activity. To identify the immune absorption activity, a varying degree of UV irradiation was applied to the cells of red blood and leukocytethrombocyte [47]. Immunoabsorption activity was increased spontaneously when irradiation was conducted in these systems. But, this was not a permanent effect since this property was decreased in the leucocyte system after 2 days.

Poly-dextran was used to determine the decreased level of erythrocytes of the cell surfaces during UV irradiation. This helped transfused erythrocytes for better survival [48]. To identify the superior effect of auto-transfused blood after the exposure of UV irradiation, modifications of the structures of the erythrocytes was helpful [49]. They demonstrated that UV irradiation can change the volume of the cell and the potential of the cell membrane of erythrocytes. However, a high dose of UV can decrease the production of hydrogen peroxide [50].

UBI has effects on neutrophils. It has been found that a small dose of UV $\left(0.1 \mathrm{~J} / \mathrm{cm}^{2}\right)$ enhances the concentration of hydrogen peroxide by the biggest polymorphonuclear leukocytes. The function of UBI through the assistance of neutrophils to accelerate the production of reactive oxygen species (ROS) can be stopped using numerous molecules including arachidonic acid, lysophosphatidylcholine, and $\alpha$-tocopherol [51]. The high amount of IC-IgG and $\operatorname{IgM}$ or low IC-IgM demonstrated an opposite property in inflammatory diseases when an increased UBI was given to auto-transfusion blood [52].

Due to the iNOS enzyme triggering, the production of nitric oxide (NO) by neutrophils was realized [53]. A fresh synthesis of NO is possible of UV irradiation, and this method generates TNF-alpha. UV irradiation with a small dose of $75.5 \mathrm{~J} / \mathrm{m}^{2}$ maintained the physiological homeostasis. A high dose of 755 to $2265 \mathrm{~J} / \mathrm{m}^{2}$ given to neutrophils caused damage by enhancing the amount of the breakdown product of NO. Cycloheximide because of its protein inhibition properties can stop the activation of iNOS and NO in the presence of UV irradiation. A direct relationship exists between NO and TNF-alpha concentration, and this can be found from experiments on a high dose of UV-irradiation $\left(755 \mathrm{~J} / \mathrm{m}^{2}\right)$ against neutrophils [53].

An experiment on UV for 30 days was performed in rabbits [54]. It was seen that the generated chronic stress is due to a combination of hydrodynamic and UBI affecting neutrophils and eliminating coagulation. UBI helped to improve the body's performance against hydrodynamic and unpredictable stress. UBI helped to enhance the organization and process structure in the activation of neutrophils stopped the coagulation of blood and changed the atherogenic condition [54].

UBI has effects on lymphocytes, T-cells, and B-cells. UBI generally helps to decrease lymphocyte viability. The UVC irradiation is believed to be the most efficient among three UV spectral ranges. The cell budding activity can be stopped by the UVB and UBC radiation. These radiations can also minimize antigen-producing ability of the component of the cells. Numerous properties including cell-surface interaction, calcium mobilization method, cytokine production/release, and a few sub-cellular processes can be modified by UV irradiation [55].

The "Comet assay" was used to identify DNA-strand breakage because of single-cell gel electrophoresis. This was an evidence of DNA repair, indicating that lymphocytes were highly fragile to this UVB irradiation. The effects of UVB radiation on this observation indicated the possibility that UVB may contribute to immunesuppression via a significant effect on extracapillary T-lymphocytes [56].

Interestingly, either the Th1 or Th2 or the CD4 or CD8 T-cells can be affected by the UVB irradiation. The photoirradiation is not seen. However, a significant number of T-cells are killed within 48 to $72 \mathrm{~h}$ with a low dose of UVB irradiation (LD50 $0.5-1 \mathrm{~mJ} / \mathrm{cm}^{2}$ ) [57]. A compatible dose-dependent reduction of cytokinesis noted after 3 days of irradiation. This is because of a direct relationship between the loss of viability and the production of cytokine. Interestingly, the pattern and ratio of CD4 and CD8 are not altered compared to the non-radiated control group. This suggests that the T-cell subsets were not selectively affected.

The UV irradiation is capable of inducing phosphorylation of tyrosine in $\mathrm{B}$ cells through a crossattachment with the immunoglobulin of the surface. This observation is, in fact, similar to the production of calcium ion in T cells. On this basis, it indicates that UV irradiation of lymphocytes activates phosphorylation of tyrosine and calcium ion signals. Therefore, the calcium ion channels in the membrane of the lymphocytes are affected due to UV irradiation. This irradiation destroys DNA by activating cellular signal-transduction pathways. On the other hand, based upon the dose, the UV irradiation activates phosphorylation of tyrosine in lymphocytes and controls calcium ion signal in Jurkat T cells. Moreover, the picture immunoglobulin of the surface remains identical to the UV-promoted tyrosine phosphorylation in B cells. It is shown that $\mathrm{CD}+$ and $\mathrm{CD} 8+\mathrm{T}$ cells can react during UV irradiation [58]. 
Following a similar study, Spielberg et al. [59] showed that UV-induced lymphocyte inhibition indicated an alteration of calcium ion homeostasis when comparing UV with gamma irradiation. Gamma radiation has different properties on lymphocyte membranes [59]. Besides, the presence of calcium channels in the membrane of lymphocyte can be found by the indo- 1 staining and cytofluorometry technique. Intracellular calcium ion $\left[\mathrm{Ca}^{2+}\right]$ i kinetics was estimated in human peripheral blood leukocytes during UVC or UB irradiation. Jurkat cells were used as a standard in this functional assay. The UV-induced concentration increase of $\left[\mathrm{Ca}^{2+}\right] \mathrm{i}$ was mainly possible because of incoming of extracellular calcium. The T-cells were more affected than non-T-cells due to this process. The concentration of $\left[\mathrm{Ca}^{2+}\right] \mathrm{i}$ was increased within 2 to $3 \mathrm{~h}$ of irradiation. A dose-dependent behavior was observed in this experiment, and a maximum point was reached for both UVB and UVC. UV induced a significant $\left[\mathrm{Ca}^{2+}\right]$ i growth in T-cells than in non-T cells, and this increase is because of the activity of the extracellular calcium. The intensity of UV irradiation on the plasma membrane decreased its sensitivity to react with certain lectins (phytohemagglutinin) in the cultures of mixed leukocytes.

Several studies indicated that lymphocytes irradiated by UVR were unable to create genetically different cells in lymphocyte culture [60-62]. For lymphocyte activation, clusters obtained after allogeneic or mitogenic method with dendritic cells were necessary. UV irradiation of dendritic cells was able to prevent the creation of clusters and inhibit lymphocyte production [63].

It was found that the induction of the DNA repair process required UVC of 2 and $16 \mathrm{~J} / \mathrm{cm}^{2}$ [64]. An evaluation was performed with lymphocytes that were irradiated or without any irradiation among 51 people. Repair synthesis by UVC irradiation at various doses was measured by evaluating $\left[{ }^{3} \mathrm{H}\right]$ thymidine along with hydroxyurea. The results became identical irrespective of the age of the donors.

UV was able to create differentiation in lymphocytes and activates DNA repairing process [65]. A subjection to UV irradiation had superior effects than methyl methanesulfonate (MMS) concerning the synthesis of unscheduled DNA. This method became efficient when MMS was given before UV irradiation. It was believed that MMS caused DNA repair through the alkylation of polymerase [66]. Light-induced modification of HLA-D/DR antigens was involved in the increased function of immune component cells. Photoaltered lymphocytes were obtained from a variety of origins including irradiated and non-irradiated blood [67].

Before transfusion, the UBI is capable of inhibiting the immune system and stopping organ rejection in an animal model. A specific amount of total body irradiation and donor marrow cells in the presence of blood was used for this experiment. This in vivo test was conducted in dogs.
The control group of animals that was permeated with blood failed to accept the bone marrow grafts. But, acceptance was seen in the group that was given UV-mediated blood before the transplantation. UV irradiation on blood prevented the activation of lymphocyte by eliminating a crucial DC-dependent signal [68].

Transfusion of UV-irradiated blood to patients before heart transplantation can be performed provided there is a deficiency in immune response, and to minimize lymphocyte-mediated rejection [69]. Different rat species (ACI, Lewis, and W/F) were studied to execute heart transfer. The ACI rats received Lewis's heart, and it was transfused with donor type of blood in the presence or absence of UV irradiation at different weeks period. The occurrence of a lymphocyte reaction indicated that the ACI group was weaker compared to Lewis counterpart. A consistent result was observed in the other two groups. Also, children who have rhesus-conflict hemolytic disorder respond positively to the presence of UV irradiation [70].

The UBI has effects on the members of the mononuclear phagocyte system. Four varieties of deoxyribonucleosides are used to improve the phagocytic activity of UVBirradiated mononuclear cells [71].

Activation of phagocytic ( $\mathrm{PhA}$ ) functions is a crucial pathway in immunocorrection by UV irradiation of blood treatment. A mixture of irradiated and non-irradiated blood was examined for PhA functions [72]. This study indicated an increase of 1.4-1.7 times of PhA. This suggests that monocytes and granulocytes can be improved by mixing UV-irradiated blood to people. The increased phagocytic functions are dependent on the initial amount and may change simultaneously due to structural alterations of the components present in the cell surface [72].

UV irradiation can increase the phagocytic power of human monocytes and granulocytes. The "integrated phagocytic index" increases based upon the proportion of the irradiation dose. A lower starting level may increase subsequently accumulating UV irradiation [73].

The UVB can change Langerhans cell (LC) or splenic adherent cells from immunogenic morphology to a tolerogenic morphology. This is possible when the antigenpresenting cells were LC or SAC [74]. Irradiation of $200 \mathrm{~J} / \mathrm{cm}^{2}$ was given to LC and AC. Consequently, nonresponsiveness was noted when UV-LC or UV-SAC are mixed with Th1 cells. It should be noted that the loss of responsiveness was not because of the generation of soluble suppressor factors. This was long-lasting, Ag-specific, and MHC-restricted. This finding was explained due to the failure of a costimulatory signal which was possible by UVB irradiation. This explanation was supported because UVB-LC or UVB-SAC did not help unresponsiveness.

UBI has effects on platelets. Low UV doses are associated with low hydrogen peroxide production in platelets. The 
hydrogen peroxide production increases as the dose increase above $0.4 \mathrm{~J} / \mathrm{cm}^{2}$. Pamphilon et al. [75] demonstrated that platelet concentrates (PC) become non-immunogenic following UVR and 5 days of storage in sterilized cell containers. The concentration of lactate, $\beta$-thromboglobulin, and platelet factor increase after UV. But, the glucose level becomes lower with a $3000 \mathrm{~J} / \mathrm{m}^{2}$ irradiation dose of $310 \mathrm{~nm}$ mean wavelength [75]. UVB irradiation of PC decreases the CD14 and increases the loss of monocytes. This observation may be due to an inhibition process that up-regulates ICAM-1 and HLA-DR [76]. But, UV irradiation of PC reduced the immunological response in a cell suspension [77-79].

UBI has effects on low-density lipoprotein (LDL) and lipids. The UV irradiation is relevant to lipid peroxidation of blood cells [80]. This occurred at the membrane of the cells. UV irradiation of blood can activate arachidonic acid to get metabolized by cyclooxygenase. This process can initiate the lipid autoperoxidation towards free radicals and the photolysis of the photooxidants. The lipid photoperoxidation method produces lipid hydroperoxides.

UV-irradiated lipid emulsion increases ROS by monocytes. This process creates greatly atherogenic oxidized LDL in the blood. Rabbits were injected with a UV lightoxidized parenteral lipid emulsion, lipofundin. Then, blood samples were taken with EDTA after a specific time of the lipofundin treatment. The UV-oxidized lipofundin showed reduced chemiluminescence from monocytes relative to a $\mathrm{Fe}^{3+}$-oxidized lipofundin. But, the effect of lipofundin treated with UV light lasted 2.3 times longer. UV-oxidized lipofundin can effectively activate $\mathrm{H}_{2} \mathrm{O}_{2}$ production than monocyte-oxidized LDL under identical conditions. The lipid peroxide amount was increased after the injection of oxidized lipofundin. In contrast, such a difference was not observed in monocyte-oxidized human LDL [81].

Salmon et al. [82] observed that UVB 280 to $315 \mathrm{~nm}$ wavelength irradiation can damage the LDL and the tryptophan (Trp) in high-density lipoprotein (HDL). The TBARS method was used to identify the photooxidation of tryptophan which is associated with the peroxidation of lowdensity and high-density lipoprotein unsaturated fatty acids. UVB is also able to destroy vitamin $\mathrm{E}$ and carotenoids. But, UVA radiation is unable to destroy tryptophan.

The lipoproteins contained in the suction blister fluid of healthy humans were oxidized by UV radiation of 290 to $385 \mathrm{~nm}$ wavelength. This experiment well simulates the interstitial fluid feeding of the epidermal cells. It was found that apolipoprotein B of LDL and apolipoprotein A-I and II of HDL undergone modifications underneath UV irradiation. Similar irradiation with wavelengths 290 to $385 \mathrm{~nm}$ modified the Trp (tryptophan) residue of serum albumin required to photo-oxidation. UVA irradiation of undiluted suction blister fluid produced A-I aggregation. The lipoproteins were not broken. UV irradiation of suction blister fluid was able to make a fragment of antigenic apolipoprotein B, and then, it was polymerized. Reactive oxygen radicals in the suction blister fluid resulted from the lipid peroxidation occurred in the HDL. UV light irradiation may be relevant to produce inflammation and degeneration by inducing photo-oxidation of lipoprotein. This may lead to systemic effects [83].

The redox status of this system is important. It is discovered that, depending on the dose, the UV irradiation can stimulate the myeloperoxidase (MPO) and the NADPHoxidase enzymes in donor blood [84]. Two doses of UV light chosen were 75.5 and $151.0 \mathrm{~J} / \mathrm{m}^{2}$. The higher dose triggered much more free radicals and $\mathrm{H}_{2} \mathrm{O}_{2}$. Two groups were divided based on MPO function and UV light dose. In group 1, the low enzyme activity increased following UV exposure at 75.5 and $151.0 \mathrm{~J} / \mathrm{m}^{2}$. In group 2, the MPO activity conversely decreased. Increasing the dose, the activity of MPO did not increase. Lipid peroxidation (LPO) was also evaluated after UV exposure of the blood. Two groups were separated based on the blood content of LPO products and the dose of UV exposure. UV irradiation at low concentration $\left(75.5-151.0 \mathrm{~J} / \mathrm{m}^{2}\right)$ decreased initially the high LPO values but increased initially low LPO values. In phagocytes, NADPH-oxidase works as a photo-acceptor for UV light. Irradiation produces augmented superoxide production and decreased intracellular $\mathrm{pH}$ activating an enzyme complex. UBI may prevent damage by free radicals by improving the activity of numerous antioxidants. After spinal cord injury in rabbits, 186 rabbits were divided into control, blood transfusion, injured, and UV treatment groups. UV irradiation of wavelength $253.7 \mathrm{~nm}$ and dose $5.68 \mathrm{~mW} / \mathrm{m}^{2}$ was used for the treatment group over 48 to $72 \mathrm{~h}$ following surgery for spinal cord injury. Measurements were taken of free radical signals (FR) as well as enzymatic activity of malondialdehyde (MDA), superoxide dismutase (SOD), and glutathione peroxidase (GSH-PX). It has been found that superoxide dismutase and glutathione peroxidase became higher in the treatment group. But, the FR and MDA of this group decreased compared to the other subdivisions. This suggests that UBI decreased the content of MDA and FR in the spinal cord tissue. These two factors also responsible for higher SOD activity and increased GSH-PX [85].

The mechanisms of UBI have always created confusion for the general public and medical professionals. It is because germicidal UV light (UVC) is employed to maintain the sanity of many items. It is used to sterilize water, or disinfect surfaces, to control infection [19]. Therefore, many believe that the UBI acts by killing the pathogens, bacteria, viruses, or other microorganisms that may be present in the body. But, no evidence supports this belief. Therefore, the mechanisms of action of UBI must be found through some other actions UV has on the various components of blood. 
Of course, the mechanisms of action of UBI are many and complex. After having proposed some of the ways UBI affects the various components of the blood, we attempt to draw a few general conclusions. First, UBI exemplifies "hormesis" or "biphasic dose-response" techniques. This phenomenon is well-reviewed [86, 87]. In principle, any toxic chemical substance, any toxic drug, or any other attack, such as ionizing radiation, hyperthermia, or oxidative stress, may become beneficial, protective, and therapeutic, if the dose is low enough. If the dose is high, the benefits or effects may disappear. This is established in the Knott's original experiments on dogs where only 5 to $7 \%$ of the total blood volume was the optimal amount irradiated.

UBI may have three different types of effects on different types of blood. In the case of neutrophils, monocytes, macrophages, and dendritic cells, UBI activates phagocytosis, increases the secretion of NO and reactive nitrogen species, and converts the DC phenotype from immunogenic to tolerogenic. Perhaps this reduces the effects of a cytokine storm. In the case of lymphocytes, the actions of UBI is to inhibit/kill various types of lymphocytes. This is established because the cell-death pathways and the apoptotic signaling are found in lymphocytes. The killing of the lymphocytes can also reduce inflammation. UBI can also oxidize blood lipids and lipoproteins. This increases oxidative stress. A short burst of oxidative stress may be beneficial. A continued chronic level of oxidative stress is detrimental. Many antioxidant defenses become up-regulated after brief exposure to oxidative stress. This is one of the fundamental mechanisms responsible for many aspects of hormesis. The oxidative function of UBI has similarities with ozone therapy and oxygen therapy.

\section{Discussion and Conclusions}

UV to disinfect may certainly be used also for SARS-CoV-2, and far-UV lamps may certainly be used to deactivate airborne viruses in rooms, offices, and walkways of shopping centers, hospitals, universities, public buildings, companies, or airports. Specific safety and efficacy for SARS-CoV-2 are however still unproven.

UBI has potentially much more rewarding uses, competing with both antivirals and vaccines. However, it suffers from the lack of recent developments, and need specific trials to understand if it maybe works. UBI was used first in 1928. It has been used extensively especially during the 1940s and 1950s. In these two decades, it has been employed as a treatment option for many different diseases including tuberculosis, asthma, pneumonia or septicemia, arthritis, or poliomyelitis [88]. With the success of antibiotics, the use of UBI declined to be almost completely forgotten. The best way of action against SARS-CoV-2 must be completely discovered.

UBI increases venous oxygen in the case of depressed blood oxygen values. It improves resistance to acute and chronic viral and bacterial infections. It has rapid detoxifying and anti-inflammatory effects. It has a regulatory effect on the autonomic nervous system. It inactivates viruses while preserving the opportunity to use their fragments as antigens. The photoluminescence therapy in general is an immune system response modulator affecting the antigenic structure in blood cells. Recently, UBI has shown promises for blood cancer treatment (for example, T cell lymphomas [89-92], leukemia [93]), viral infections (for example, hepatitis $C[94,95]$ ), or bacterial infections (for example, tuberculosis [96-99]).

In the latest tests $[94,95]$, UBI also revealed significant hepatitis $\mathrm{C}$ virus (HCV) viral load reduction and improved liver function in a large percentage of the patients in the small trial. Five treatments were administered to a small trial of only 10 patients for 3 weeks [95]. A modified Knott Hemo-Irradiator was used. After treatments in 9 of the patients, the mean viral load reduction was $-56.0 \%$ and the mean change in log viral load was -0.60 . Seven of 10 patients demonstrated a $>0.49 \log$ reduction in viral load. No significant adverse event was reported. Two patients who also had psoriasis improved for this other pathology.

UBI recently also showed efficacy in a 2006 animal study still unpublished but mentioned also in [94] on influenza and simian immunodeficiency viral infection. The treatment of influenza-infected animals produced improvement in both the viral load and the pulmonary function. After a high infectious dose of 5000 TCID50, only mild symptoms were observed in the treated group after day 9 , while severe symptoms were developed in the untreated group after day 6 , unresolved after the 13 days of the study length. Treated infected animals exhibited a better ability to breath than the untreated animals.

A novel UBI device-the Knott Hemo Irradiator, designed in 1928-should be certainly developed and studied for the treatment of SARS-CoV-2 infections for which there are few treatment options. Specific trials should be carried out starting from animal models to verify safety and efficacy. The size of the trials should be large enough to be statistically significant, and it should be double-blind, placebo, fully controlled trials. The mechanisms of action must be better studied, as they are presently still supposed more than proven. Definitively, the cure that time forgot may return helpful with novel pathologies, novel viral infections such as SARS-CoV-2, or antibiotic-resistant bacteria. This is a fascinating opportunity for which we may only advocate more fundamental studies on the direct and indirect influence of UV light on the many aspects of blood and specifically to SARS-CoV-2 the ability to build antibodies. 
We have reviewed a highly intriguing area of research, which is also a call for action in a time when an old method of treatment of patients with sepsis may have greater importance in the face of new challenges such as SARSCoV-2. The Knott blood irradiation was used with amazing clinical successes in the 1930s to the 1950s but fell out of favor as antibiotic therapy became increasingly available. Given the current state of antibacterial and antiviral therapies, however, it may indeed be time to re-visit these issues and to do so with the modern tools available to the scientific community to elucidate the mechanism of action and utility in treating septic patients.

We must mention the existence of blood photochemical treatment systems that are commercially available today and are used to prevent transfusion transmission of diseases. These include the Intercept system which employs psoralen and UV light, the Mirasol system which employs riboflavin and UV light, and the Theraflex system which employs UVC light alone. These systems and the findings from work which have been conducted in the past 20 years may be relevant to the reviewed topic and possibly even serve as launching points for the initiation of renewed research efforts in this field.

At present, there is no experience reported in the literature about specific uses of UBI for SARS-CoV-1, MERS, and SARS-CoV-2 viral infections. A search in clinicaltrials.gov for "Ultraviolet Blood Irradiation" does not return any result. However, a search for "Extracorporeal Photopheresis" still returns 69 results. The major reason for this is the skepticism by mainstream media towards "the cure that time forgot" UBI, which has been only used in recent times by the alternative medicine community, and the unawareness of the ECP development, that, opposite, is still used by the orthodox medical community with further improvements still being sought. While there is no reason to propose mass use of UBI or ECP-based protocols against SARS-CoV-2 infection, it is certainly warranted to perform further basic studies about UBI and ECP mechanisms, and then conduct trials for specific applications including SARSCoV-2 infection.

\section{Compliance with Ethical Standard}

Conflict of interest The authors declare that they have no conflict of interest.

\section{References}

1. Welch D et al (2018) Far-UVC light: a new tool to control the spread of airborne-mediated microbial diseases. Sci Rep 8:2752

2. Reed NG (2010) The history of ultraviolet germicidal irradiation for air disinfection. Public Health Rep 125:15-27
3. Hollaender A, du Buy HG, Ingraham HS, Wheeler SM (1944) Control of air-borne microorganisms by ultraviolet floor irradiation. Science 99:130-131

4. Kowalski, W. J. Ultraviolet germicidal irradiation handbook: UVGI for air and surface Disinfection, (Springer, 2010).

5. Wells WF, Fair GM (1935) Viability of B. coli exposed to ultraviolet radiation in air. Science 82:280-281

6. Conner-Kerr TA, Sullivan PK, Gaillard J, Franklin ME, Jones RM (1998) The effects of ultraviolet radiation on antibioticresistant bacteria in vitro. Ostomy Wound Manage 44:50-56

7. Budowsky EI, Bresler SE, Friedman EA, Zheleznova NV (1981) Principles of selective inactivation of viral genome. I. UV-induced inactivation of influenza virus. Arch Virol 68:239-247

8. Setlow RB, Grist E, Thompson K, Woodhead AD (1993) Wavelengths effective in induction of malignant melanoma. Proc Natl Acad Sci USA 90:6666-6670

9. Balasubramanian D (2000) Ultraviolet radiation and cataract. J Ocul Pharmacol Ther 16:285-297

10. Buonanno $\mathrm{M}$ et al (2013) 207-nm UV light - a promising tool for safe low-cost reduction of surgical site infections. I: in vitro studies. PLoS ONE 8:e76968

11. Buonanno $\mathrm{M}$ et al (2016) 207-nm UV light-a promising tool for safe low-cost reduction of surgical site infections. II: in-vivo safety studies. PLoS ONE 11:e0138418

12. Buonanno $\mathrm{M}$ et al (2017) Germicidal efficacy and mammalian skin safety of 222-nm UV light. Radiat Res 187:483-491

13. Matafonova GG, Batoev VB, Astakhova SA, Gómez M, Christofi $\mathrm{N}$ (2008) Efficiency of $\mathrm{KrCl}$ excilamp (222 nm) for inactivation of bacteria in suspension. Lett Appl Microbiol 47:508-513

14. Sosnin EA, Avdeev SM, Kuznetzova LVA (2005) Lavrent'eva Bactericidal Barrier-Discharge $\mathrm{KrBr}$ Excilamp. Instruments and Experimental Techniques 48:663-666

15. Wang D, Oppenländer T, El-Din MG, Bolton JR (2010) Comparison of the disinfection effects of vacuum-UV (VUV) and UV light on Bacillus subtilis spores in aqueous suspensions at 172, 222 and $254 \mathrm{~nm}$. Photochem and Photobiol 86:176-181

16. McDevitt JJ, Rudnick SN, Radonovich LJ (2012) Aerosol susceptibility of influenza virus to UV-C light. Appl Environ Microbiol 78:1666-1669

17. Beck SE, Hull NM, Poepping C, Linden KG (2017) Wavelengthdependent damage to adenoviral proteins across the germicidal UV spectrum. Environ Sci Technol 52(1):223-229

18. Beck SE et al (2016) Comparison of UV-induced inactivation and RNA damage in MS2 phage across the germicidal UV spectrum. Appl Environ Microbiol 82:1468-1474

19. Hamblin, M.R. Ultraviolet irradiation of blood: "the cure that time forgot"? In: Ahmad S. (eds) Ultraviolet light in human health, diseases and environment. Advances in Experimental Medicine and Biology, vol 996. (Springer, Cham, 2017).

20. Knott EK (1948) Development of ultraviolet blood irradiation. The American Journal of Surgery 76(2):165-171

21. Hancock VK, Knott EK (1934) Irradiated blood transfusion in the treatment of infections. Northwest Med 33:200

22. Miley G, Christensen JA (1947) Ultraviolet blood irradiation therapy: further studies in acute infections. The American Journal of Surgery 73(4):486-493

23. Miley G (1944a) Ultraviolet blood irradiation therapy (Knott technic) in non-healing wounds. The American Journal of Surgery 65(3):368-372

24. Miley GP (1946) Recovery from botulism coma following ultraviolet blood irradiation. The Review of gastroenterology 13:17

25. Miley GP, Seidel RE, Christensen JA (1946) Ultraviolet blood irradiation therapy of apparently intractable bronchial asthma. Arch Phys Med Rehabil 27:24-29 
26. Miley G (1943a) The control of acute thrombophlebitis with ultraviolet blood irradiation therapy. The American Journal of Surgery 60(3):354-360

27. Miley G (1944b) Efficacy of ultraviolet blood irradiation therapy in the control of staphylococcemias. The American Journal of Surgery 64(3):313-322

28. Miley G (1944c) Ultraviolet blood irradiation therapy in acute poliomyelitis. Arch Phys Ther 25:651-656

29. Miley G (1943b) Disappearance of hemolytic staphylococcus aureus septicemia following ultraviolet blood irradiation therapy: Knott technic. The American Journal of Surgery 62(2):241-245

30. Miley G (1942a) The Knott technic of ultraviolet blood irradiation in acute pyogenic infections: a study of 103 cases with clinical observations on the effects of a new therapeutic agent. Anesthesiology: The Journal of the American Society of Anesthesiologists 3(4):485-485

31. Miley G (1944d) Present status of ultraviolet blood irradiation (Knott technic). Arch Phys Ther 25:368-372

32. Miley G (1943c) Ultraviolet blood irradiation therapy. Am J Bact 45:303

33. Miley G (1942b) Ultraviolet blood irradiation therapy (Knott technic) in acute pyogenic infections. The American Journal of Surgery 57(3):493-507

34. Miley GP, Rebbeck EW (1943) The Knott technic of ultraviolet blood irradiation as a control of infection in peritonitis. Rev Gastroenterol 10:1-26

35. Miley GP, Seidel RE, Christensen JA (1943) Preliminary report of results observed in eighty cases of intractable bronchial asthma. Arch Phys Ther 533(24):42-53

36. Barrett HA (1940) The irradiation of autotransfused blood by ultraviolet spectral energy: results of therapy in 110 cases. Med Clin North Am 24(3):723-732

37. Barrett HA (1943) Five years' experience with hemo-irradiation according to the Knott technic. The American Journal of Surgery 61(1):42-53

38. Rebbeck EW, Walther RA (1942) Double septicemia following prostatectomy treated by the knott technic of ultraviolet blood irradiation: Case report. The American Journal of Surgery 57(3):536-538

39. Rebbeck EW (1943a) Preoperative hemo-irradiations. The American Journal of Surgery 61(2):259-265

40. Rebbeck EW (1941) Ultraviolet irradiation of autotransfused blood in the treatment of puerperal sepsis. TheAmerican Journal of Surgery 54(3):691-700

41. Rebbeck EW (1942) Ultraviolet irradiation of autotransfused blood in the treatment of postabortional sepsis. The American Journal of Surgery 55(3):476-486

42. Rebbeck EW (1943b) Ultraviolet irradiation of blood in the treatment of Escherichia coli septicemia. Archives of Physical Therapy $24: 158-167$

43. Olney RC (1946) Ultraviolet blood irradiation in biliary disease: Knott method. The American Journal of Surgery 72(2):235-237

44. Olney RC (1947) Ultraviolet blood irradiation treatment of pelvic cellulitis: Knott method. The American Journal of Surgery 74(4):440-443

45. Olney RC (1955) Treatment of viral hepatitis with the Knott technic of blood irradiation. Am J Surg 90(3):402-409

46. Kabat, I. A., Sysa, J., Zakrzewska, I., \& Leyko, W. Effect of UV-irradiation of shifts of energy-rich phosphate compounds: ADP, ATP and AXP in human red blood cells represented by a trigonometrical polynomial. Zentralblatt fur Bakteriologie, Parasitenkunde, Infektionskrankheiten und Hygiene. Erste Abteilung Originale. Reihe B: Hygiene, praventive Medizin, 162(3-4), 393-401 (1976).

47. Vasil'eva ZF, Samol̆lova KA, Shtil'bans VI, Obolenskaia KD, Vitiuk NG (1991) Changes of immunosorption properties in the blood and its components at various times after UV-irradiation. Gematol Transfuziol 36(5):26-27

48. Samoĭlova KA, Snopov SA, Belisheva NK, Kukuĭ LM, Ganelina IE (1987) Functional and structural changes in the surface of human erythrocytes after irradiation by different wave lengths of UV rays. III. The immediate effect of the autotransfusion of UV-irradiated blood. Tsitologiia 29(7):810-817

49. Snopov SA, Aritsishevskaia RA, Samoulova KA, Marchenko AV, Dutkevich IG (1989) Functional and structural changes in the surface of human erythrocytes following irradiation with ultraviolet rays of various wave lengths. V. Modification of the glycocalyx in autotransfusions of UV-irradiated blood. Tsitologiia 31(6):696-705

50. Ichiki H, Sakurada H, Kamo N, Takahashi TA, Sekiguchi $S$ (1994) Generation of active oxygens, cell deformation and membrane potential changes upon UV-B irradiation in human blood cells. Biological and Pharmaceutical Bulletin 17(8):1065-1069

51. Savage JE, Theron AJ, Anderson R (1993) Activation of neutrophil membrane-associated oxidative metabolism by ultraviolet radiation. Journal of investigative dermatology 101(4):532-536

52. Ivanov EM, Kapshienko IN, Tril NM (1989) Effect of the UV irradiation of autologous blood on the humoral link in the immune response of patients with chronic inflammatory processes. Vopr Kurortol Fizioter Lech Fiz Kult 1:45-47

53. Artiukhov VF, Gusinskaia VV, Mikhileva EA (2005) Level of nitric oxide and tumor necrosis factor-alpha production by human blood neutrophils under UV-irradiation. Radiats Biol Radioecol 45(5):576-580

54. Zor'kina AV, Inchina VI, Kostin I (1996) Effect of UV-irradiation of blood on the course of adaptation to conditions of hypodynamia. Patologicheskaia fiziologiia i eksperimental'naia terapiia 2:22-24

55. Deeg HJ (1988) Ultraviolet irradiation in transplantation biology. Manipulation of immunity and immunogenicity Transplantation 45(5):845-851

56. Arlett CF et al (1993) Hypersensitivity of human lymphocytes to UV-B and solar irradiation. Can Res 53(3):609-614

57. Teunissbn M, Sylva-Stehnland RMR, Bos JD (1993) Effect of low-dose ultraviolet-B radiation on the function of human $\mathrm{T}$ lymphocytes in vitro. Clin Exp Immunol 94(1):208-213

58. Schieven GL, Ledbetter JA (1993) Ultraviolet radiation induces differential calcium signals in human peripheral blood lymphocyte subsets. Journal of immunotherapy with emphasis on tumor immunology: official journal of the Society for Biological Therapy 14(3):221-225

59. Spielberg H, June CH, Blair OC, Nystrom-Rosander C, Cereb N, Deeg H (1991) JUV irradiation of lymphocytes triggers an increase in intracellular $\mathrm{Ca} 2+$ and prevents lectin-stimulated $\mathrm{Ca} 2+$ mobilization: evidence for UV-and nifedipine-sensitive Ca2+ channels. Exp Hematol 19(8):742-748

60. Pamphilon DH, Corbin SA, Saunders J, Tandy NP (1989) Applications of ultraviolet light in the preparation of platelet concentrates. Transfusion 29(5):379-383

61. Lindahl-Kiessling K, Säfwenberg J (1971) Inability of UV-irradiated lymphocytes to stimulate allogeneic cells in mixed lymphocyte culture. Int Arch Allergy Immunol 41(5):670-678

62. Slater LM, Murray S, Liu J, Hudelson B (1980) Dissimilar effects of ultraviolet light on HLA-Dand HLA-DR antigens. Tissue Antigens 15(5):431-435

63. Aprile J, Deeg HJ (1986) Ultraviolet irradiation of canine dendritic cells prevents mitogen-induced cluster formation and lymphocyte proliferation. Transplantation 42(6):653-660

64. Kovacs E, Weber W, Müller H (1984) Age-related variation in the DNA-repair synthesis after UV-C irradiation in unstimulated 
lymphocytes of healthy blood donors. Mutation Research/DNA Repair Reports 131(5-6):231-237

65. Genter EI, Zhestianikov VD, Mikhel'son VM, Prokof'eva VV (1984) DNA repair in the UV irradiation of human peripheral blood lymphocytes (healthy donors and xeroderma pigmentosum patients) in relation to the dedifferentiation process in phytohemagglutinin exposure. Tsitologiia 26(5):599-604

66. Genter EI, Mikhel'son VM, Zhestianikov VD (1989) The modifying action of methylmethane sulfonate on unscheduled DNA synthesis in the UV irradiation of human peripheral blood lymphocytes. Radiobiologiia 29(4):562-564

67. Volgareva EV, Volgarev AP, Samoilova KA (1990) The effect of UV irradiation and of UV-irradiated autologous blood on the functional state of human peripheral blood lymphocytes. Tsitologiia 32(12):1217-1224

68. Deeg HJ, Aprile J, Graham TC, Appelbaum FR, Storb R (1986) Ultraviolet irradiation of blood prevents transfusioninduced sensitization and marrow graft rejection in dogs. Blood 67(2):537-539

69. Oluwole SF, Iga C, Lau H, Hardy MA (1985) Prolongation of rat heart allografts by donor-specific blood transfusion treated with ultraviolet irradiation. The Journal of heart transplantation 4(4):385-389

70. Vasil'eva ZF, Shtil'bans VI, Samoŭlova KS, Obolenskaia KD (1989) The activation of the immunosorptive properties of blood during its UV irradiation at therapeutic doses. Biulleten'eksperimental'noi biologii i meditsiny 108(12):689-691

71. Green MH, Waugh AP, Lowe JE, Harcourt SA, Cole J, Arlett CF (1994) Effect of deoxyribonucleosides on the hypersensitivity of human peripheral blood lymphocytes to UV-B and UV-C irradiation. Mutation Research/DNA Repair 315(1):25-32

72. Samoĭlova KA, Obolenskaia KD, Freĭdlin IS (1987) Changes in the leukocyte phagocytic activity of donor blood after its UV irradiation. II. Simulation of the effect of the autotransfusion of UV-irradiated blood. Tsitologiia 29(9):1048-1055

73. Obolenskaia KD, Freĭdlin IS, Samoǔlova KA (1987) Changes in the leukocyte phagocytic activity of donor blood after its UV irradiation. I. Its relation to the irradiation dose and initial level of phagocytic activity. Tsitologiia 29(8):948-954

74. Simon JC, Tigelaar RE, Bergstresser PR, Edelbaum D, Cruz PD (1991) Ultraviolet B radiation converts Langerhans cells from immunogenic to tolerogenic antigen-presenting cells. Induction of specific clonal anergy in CD4+ T helper 1 cells. TheJournal of Immunology 146(2):485-491

75. Pamphilon DH et al (1990) Platelet concentrates irradiated with ultraviolet light retain satisfactory in vitro storage characteristics and in vivo survival. Br J Haematol 75(2):240-244

76. Fiebig E, Lane TA (1994) Effect of storage and ultraviolet B irradiation onCD14-bearing antigen-presenting cells (monocytes) in platelet concentrates. Transfusion 34(10):846-851

77. Kahn RA, Duffy BF, Rodey GG (1985) Ultraviolet irradiation of platelet concentrate abrogates lymphocyte activation without affecting platelet function in vitro. Transfusion 25(6):547-550

78. Andreu G et al (1992) The role of UV radiation in the prevention of human leukocyte antigen alloimmunization. Transfus Med Rev 6(3):212-224

79. Tandy NP, Pamphilon DH (1991) Platelet transfusions irradiated with ultraviolet-B light may have a role in reducing recipient alloimmunization. Blood coagulation \& fibrinolysis: an international journal in haemostasis and thrombosis 2(2):383-388

80. Roshchupkin DI, Murina MA (1998) Free-radical and cyclooxygenase-catalyzed lipid peroxidation in membranes of blood cells under UV irradiation. Membrane \& cell biology 12(2):279-286
81. Görög P (1991) Activation of human blood monocytes by oxidized polyunsaturated fatty acids: a possible mechanism for the generation of lipid peroxides in the circulation. Int $\mathbf{J}$ Exp Pathol 72(2):227

82. Salmon S, Maziere JC, Santus R, Morliere P, Bouchemal N (1990) UVB-induced photoperoxidation of lipids of human low and high density lipoproteins. A possible role of tryptophan residues. Photochem Photobiol 52(3):541-545

83. Salmon S, Haigle J, Bazin M, Santus R, Maziere JC, Dubertret L (1996) Alteration of lipoproteins of suction blister fluid by UV radiation. J Photochem Photobiol, B 33(3):233-238

84. Artyukhov VG, Iskusnykh AY, Basharina OV, Konstantinova TS (2005) Effect of UV irradiation on functional activity of donor blood neutrophils. Bull Exp Biol Med 139(3):313-315

85. Dong Y, Shou T, Zhou Y, Jiang S, Hua X (2000) Ultraviolet blood irradiation and oxygenation affects free radicals and antioxidase after rabbit spinal cord injury. Chin Med J 113(11):991-995

86. Calabrese EJ, Dhawan G, Kapoor R, Iavicoli I, Calabrese V (2016) HORMESIS: a fundamental concept with widespread biological and biomedical applications. Gerontology 62(5):530-535

87. Calabrese EJ (2014) Hormesis: from mainstream to therapy. Journal of cell communication and signaling 8(4):289-291

88. Wu X, Hu X, Hamblin MR (2016) Ultraviolet blood irradiation: is it time to remember "the cure that time forgot"? J Photochem Photobiol, B 157:89-96

89. Edelson RL (1991) Photopheresis: a clinically relevant immunobiologic response modifier. Ann N Y Acad Sci 636:154-164

90. Edelson R (1989) LPhotopheresis: a new therapeutic concept. The Yale journal of biology and medicine 62(6):565

91. Edelson R et al (1987) Treatment of cutaneous T-cell lymphoma by extracorporeal photochemotherapy. N Engl J Med 316(6):297-303

92. Edelson RL (2001) Cutaneous T cell lymphoma: the helping hand of dendritic cells. Ann N Y Acad Sci 941(1):1-11

93. Tuck A, Smith S, Larcom L (2000) Chronic lymphocytic leukemia lymphocytes lack the capacity to repair UVC-induced lesions. Mutation Research/DNA Repair 459:73-80

94. Kuenstner JT, Mukherjee S, Weg S, Landry T, Petrie T (2015) The treatment of infectious disease with a medical device: results of a clinical trial of ultraviolet blood irradiation (UVBI) in patients with hepatitis $\mathrm{C}$ infection. International Journal of Infectious Diseases 37:58-63

95. Kuenstner JT, Mukherjee S, Schafer Z, Kuenstner W, Petrie T (2019) A controlled clinical trial of ultraviolet blood irradiation (UVBI) for hepatitis C infection. Cogent Medicine 6(1):1614286

96. Zhadnov VZ, Mishanov RF, Kuznetsov AA, Shprykov AS, Ryzhakova TM (1995) Effectiveness of chemotherapy in combination with electrophoresis and ultraviolet irradiation of blood in newly diagnosed patients with destructive pulmonary tuberculosis. Problemy Tuberkuleza 3:20-22

97. Shurygin AA (2009) The efficiency of ultraviolet autologous blood irradiation used in the complex therapy of infiltrative pulmonary tuberculosis in children and adolescents. Probl Tuberk Bolezn Legk 9:20-23

98. Darwin KH, Nathan CF (2005) Role for nucleotide excision repair in virulence of Mycobacterium tuberculosis. Infect Immun 73:4581-4610

99. Kuenstner JT, Chamberlin W, Naser S, Zhang HY, Wang S, Zhou WX, Duan J (2015) Resolution of Crohn's disease and complex regional pain syndrome following treatment of paratuberculosis. World Journal of Gastroenterology: WJG 21:4048-4062

100. Gonzalez AL, Berger CL, Remington J, Girardi M, Tigelaar RE, Edelson RL (2014) Integrin-driven monocyte to dendritic cell 
conversion in modified extracorporeal photochemotherapy. Clin Exp Immunol 175(3):449-457

101. Edelson RL (2014) Mechanistic insights into extracorporeal photochemotherapy: efficient induction of monocyte-to-dendritic cell maturation. Transfus Apheres Sci 50(3):322-329

102. Gottlieb SL, Wolfe JT, Fox FE, DeNardo BJ, Macey WH, Bromley PG, Rook AH (1996) Treatment of cutaneous T-cell lymphoma with extracorporeal photopheresis monotherapy and in combination with recombinant interferon alfa: a 10-year experience at a single institution. J Am Acad Dermatol 35(6):946-957

103. Bladon J, Taylor PC (1999) Extracorporeal photopheresis induces apoptosis in the lymphocytes of cutaneous T-cell lymphoma and graft-versus-host disease patients. Br J Haematol 107(4):707-711
104. Russell-Jones R (2000) Extracorporeal photopheresis in cutaneous T-cell lymphoma. Inconsistent data underline the need for randomized studies. Br J Dermatol 142(1):16-21

105. Scarisbrick JJ, Taylor P, Holtick U, Makar Y, Douglas K, Berlin G, Photopheresis Expert Group (2008) UK consensus statement on the use of extracorporeal photopheresis for treatment of cutaneous T-cell lymphoma and chronic graft-versus-host disease. Br J Dermatol 158(4):659-678

Publisher's Note Springer Nature remains neutral with regard to jurisdictional claims in published maps and institutional affiliations. 